\title{
Similarity and Practice Schedules: Contextual Interference Variables in Speech Production
}

\author{
Elisabeth P. Kee
}

Follow this and additional works at: https://researchrepository.wvu.edu/etd

\section{Recommended Citation}

Kee, Elisabeth P., "Similarity and Practice Schedules: Contextual Interference Variables in Speech Production" (2018). Graduate Theses, Dissertations, and Problem Reports. 5955.

https://researchrepository.wvu.edu/etd/5955

This Thesis is protected by copyright and/or related rights. It has been brought to you by the The Research Repository @ WVU with permission from the rights-holder(s). You are free to use this Thesis in any way that is permitted by the copyright and related rights legislation that applies to your use. For other uses you must obtain permission from the rights-holder(s) directly, unless additional rights are indicated by a Creative Commons license in the record and/ or on the work itself. This Thesis has been accepted for inclusion in WVU Graduate Theses, Dissertations, and Problem Reports collection by an authorized administrator of The Research Repository @ WVU. For more information, please contact researchrepository@mail.wvu.edu. 
Similarity and Practice Schedules: Contextual Interference Variables in Speech Production

Elisabeth P. Kee

Thesis submitted

to the College of Education and Human Services

at West Virginia University

in partial fulfillment of the requirements for the degree of

Master of Science in

The Department of Communication Sciences and Disorders

Kimberly M. Meigh, Ph.D., Chair

Dennis Ruscello, Ph.D.

Michelle Moore, Ph.D.

Department of Communication Sciences and Disorders

\author{
Morgantown, West Virginia
}

2018

Keywords: contextual interference; speech; motor learning

Copyright 2018 Elisabeth P. Kee 


\begin{abstract}
Similarity and Practice Schedules: Contextual Interference Variables in Speech Production

Elisabeth P. Kee

Purpose: This study evaluated the influence of phonemic similarity as a variable that facilitates contextual interference $(\mathrm{CI})$, a motor learning phenomenon where poor performance during training results in enhanced performance in transfer conditions. A CI effect was hypothesized: speech performance would be enhanced for nonwords with similar phonemes during the retention phase of motor learning, but only enhanced by nonwords with dissimilar phonemes in the transfer phase.

Method: Twenty-nine young adults with typical speech and hearing participated in a motorlearning study comprised of nonword repetition training followed by an immediate retention and transfer task for nonwords with similar and dissimilar phonemes. Training was counterbalanced by stimuli and participants using a within-subject repeated-measures design. Percent consonants correct was calculated to examine the effects of the different stimuli on stage of skill acquisition. Results: A CI effect was observed in this study using nonwords that varied in phonemic similarity. Participants accuracy was greatest when producing nonwords with similar phonemes during the retention task; however, during the transfer task, accuracy was greatest when producing nonwords with dissimilar phonemes.

Conclusions: The proposed hypothesis for this study was met: practicing nonwords with dissimilar phonemes lead to greater accuracy in the transfer phase of this experiment. Results indicate phonemic dissimilarity produces a contextual interference and influencing speech motor learning. Future research should determine if these results generalize to other populations, including children with typically developing language and speech skills.
\end{abstract}




\section{CONTENTS}

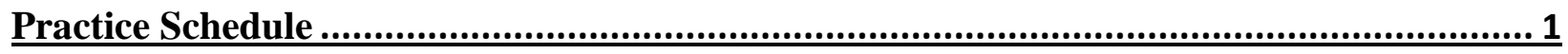

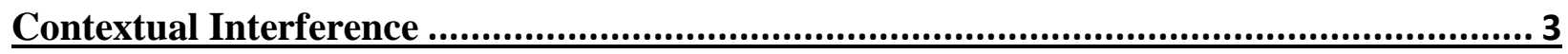

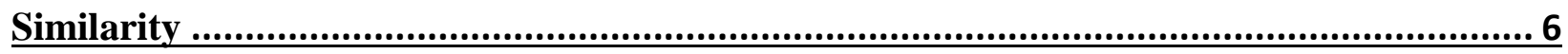

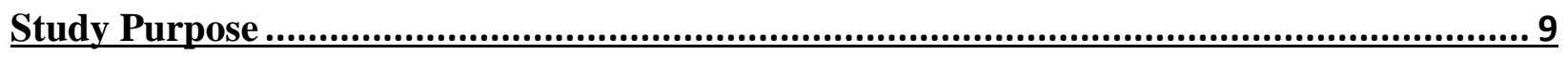

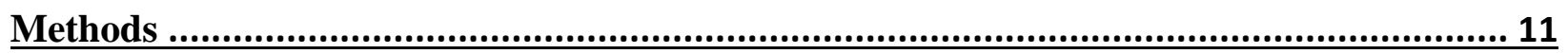

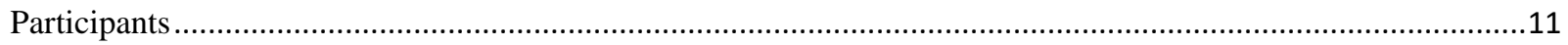

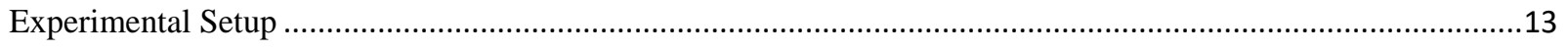

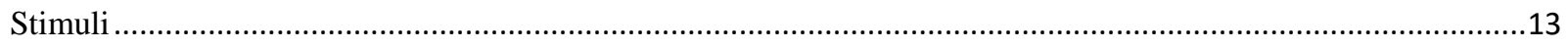

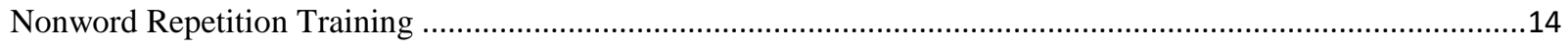

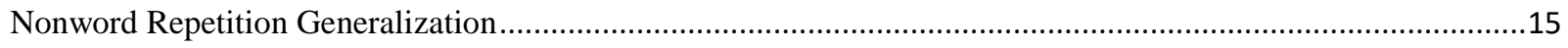

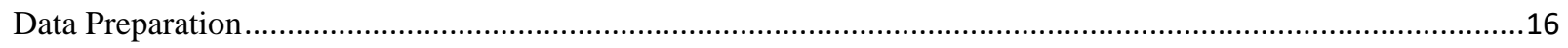

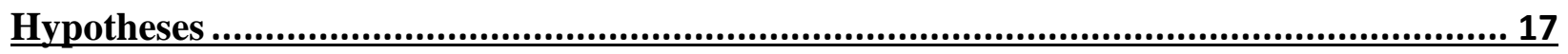

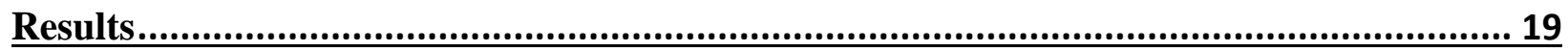

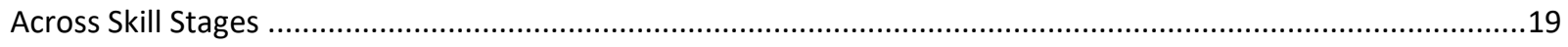

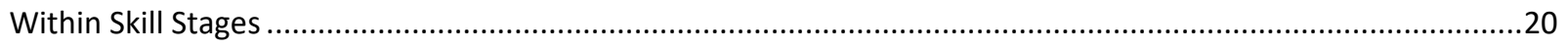

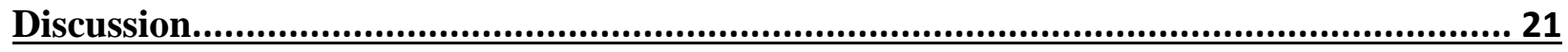

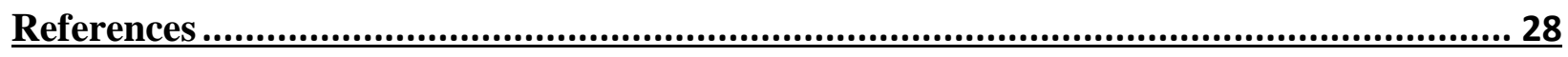

Appendix A: Pre-Screening Language Questionnaire......................................................... 35

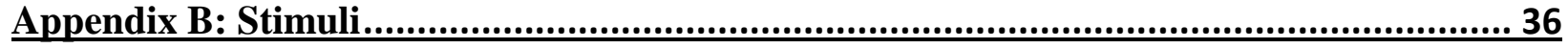

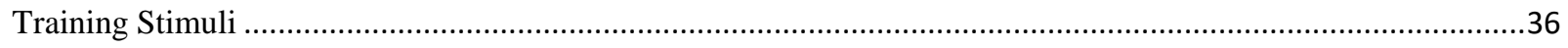

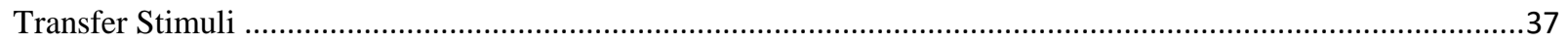




\section{PRACTICE SCHEDULE}

Speech-language pathologists have traditionally relied on practice schedule to aid treatment design and influence clinical outcomes in patients with speech disorders (e.g., Ballard et al., 2015; Maas et al., 2008). Practice schedule is defined by the order in which tasks are administered during therapy (Lee \& Simon, 2004; Maas et al., 2008; Magill \& Hall, 1990), and have traditionally been implemented in one of two ways: random or blocked practice. A random practice schedule involves practicing several different tasks consecutively in random order. For example, tasks 1, 2, and 3 are all practiced together until practice is completed (e.g., task order: 1, $3,2,3,1,2,2,1,3)$. A blocked practice schedule requires a single task to be practiced fully before moving onto the next task (e.g., task order: 1, 1, 1, 2, 2, 2, 3, 3, 3; Kantak \& Winstein, 2012; Lee \& Simon, 2004; Maas et al., 2008). From a motor learning perspective, practice schedule becomes an important variable in skill acquisition and influences the three stages of learning differently (Kantak \& Winstein, 2012; Lee \& Simon, 2004; Russell \& Newell, 2007; Schmidt, 1975).

The first stage of motor learning is the acquisition stage where training, or practice, is implemented. During practice, information regarding the movement and task is encoded into memory. It is unclear what type of processes are involved in memory encoding during practice. However, it may involve memory recognition and selection, where the actual movement is compared to the desired outcome prior to the next executed movement (Kantak \& Winstein, 2012). It has been hypothesized that practice schedule alters the encoding of motor memories (Battig, 1979). Specifically, blocked practice results in encoding the same movement pattern multiple times in succession, whereas random practice results in encoding multiple different motor memories (Kantak \& Winstein, 2012). This difference in encoding, or memory recognition and selection, has been attributed to execution differences between practice schedules. Specifically, 
blocked practice schedules result in enhanced motor performance when compared to random practice schedules (Lee \& Simon, 2004). This performance enhancement is restricted to the acquisition stage, however, and is diminished in the second stage of motor learning (Kantak \& Winstein, 2012).

During the second stage of motor learning, the retention stage, practice is concluded and motor memories are consolidated (Kantak \& Winstein, 2012). Motor learning at this stage is considered relatively permanent compared to practice, as the encoded motor memory is transferred from working memory into long-term memory (Kantak \& Winstein, 2012; Russell \& Newell, 2007). During the retention stage, a retention test (either short-term or long-term) may be administered to assess the integrity of the newly acquired motor memory (Kantak \& Winstein, 2012; Maas et al., 2008). A short-term retention test can be administered a few minutes or hours following the training stage, whereas a long-term retention task is administered days, weeks, months, or even years later (Battig, 1979). An individual's motor performance during retention varies with practice schedule, with overall enhanced performance observed with random practice (Lee \& Simon, 2004). This is in contrast to motor performance during the acquisition stage of motor learning where blocked practice resulted in enhanced performance. This paradoxical motor learning phenomenon has been termed the contextual interference (CI) effect (Battig, 1979; Lee \& Magill, 1985).

The third and final stage of motor learning is known as the transfer stage, which refers to the ability to take a previously learned skill and apply that to a new behavior (Kantak \& Winstein, 2012). This stage corresponds to the motor memory process of retrieval, where previously stored memories are used to perform a novel skill (Kantak \& Winstein, 2012). Novel skills may be adapted from previously practiced skills, skills that are related but have not been practiced, or the 
same skill that was practiced but will now be executed within a novel testing scenario (J. A. Adams, 1987; Kantak \& Winstein, 2012). The CI effect is also observed during this stage of motor learning, where random practice results in enhanced performance during transfer tasks (e.g., Lee \& Simons, 2004; Maas et al., 2008; C. H. Shea, Kohl, \& Indermill, 1990).

\section{CONTEXTUAL INTERFERENCE}

The contextual interference $(\mathrm{CI})$ effect predicts an increase in memory interference experienced during random practice, which enhances overall learning by providing practice on a variety of movement patterns (Boutin \& Blandin, 2010; Lee, Wulf, \& Schmidt, 1992; Maas et al., 2008; J. B. Shea \& Morgan, 1979). Interference, in this context, refers to the variability of the tasks being practiced between trials and the performance and memory effects resulting from this process (Kantak \& Winstein, 2012; Kruisselbrink \& Van Gyn, 2011; Magill \& Hall, 1990). In terms of practice schedule, blocked practice is hypothesized to produce low interference because the same movement pattern or task is practiced fully before moving on to a new task (e.g., task order: 1,1 , 1, 2, 2, 2, 3, 3, 3; Maas et al., 2008; Magill \& Hall, 1990; Lee \& Simon, 2004). Alternatively, random practice is hypothesized to produce high interference as the movement pattern or task changes from trial to trial (e.g., task order: 1, 3, 2, 3, 1, 2, 2, 1, 3; Maas et al., 2008; Magill \& Hall, 1990; Lee \& Simon, 2004). An increased amount of interference during acquisition increases the overall difficulty of the motor task by requiring the participant to practice a variety of movements, which in turn results in robust and flexible memory representations (Jarus, Wughalter, \& Gianutsos, 1997; Lee et al., 1992). These enhanced memories include more information than memories encoded during blocked practice, potentially providing more efficient memory retrieval during transfer tasks (Lee \& Simon, 2004). 
As stated previously, contextual interference is attributed to alterations in memory processing due to the interactions of specific variables during skill acquisition (Jarus et al., 1997). These specific variables may include practice schedules, levels of expertise (Brady, 1998; Hall, Domingues, \& Cavazos, 1994), environment (e.g., lab- versus natural-learning; Brady, 1998), verbal rehearsal (Wright, Li, \& Whitacre, 1992), type of task (e.g., speech versus typing; Kaipa, 2013), and similarity between tasks (Battig, 1979). These variables may influence contextual interference during skill acquisition of a variety of skills, including volleyball (Travlos, 2010), tennis (Landin, Hebert, \& Menickelli, 2003), visuomotor tasks (J. B. Shea \& Morgan, 1979 per Timothy D. Lee \& Simon, 2004), nonword repetition tasks (Meigh, 2017), generating word lists (Battig, 1979), and neural networks learning ballistic, targeted movement patterns (Horak, 1992). Thus, the CI effect appears to influence the different stages of skill acquisition (i.e., acquisition, retention, and transfer) similarly across motor and verbal domains (S. G. Adams \& Page, 2000; Bislick, Weir, Spencer, Kendall, \& Yorkston, 2012; Maas et al., 2008). However, despite its influence on learning, there is little consensus on how contextual interference influences memory processing.

Several hypotheses have been put forth as potential explanations for the memory processing changes resulting in the $\mathrm{CI}$ effect, and the two most prominent will be discussed: elaboration-distinctiveness and the forgetting-reconstruction hypotheses (Boutin \& Blandin, 2010; Maas et al., 2008; Simon \& Bjork, 2002). Proponents of the elaboration-distinctiveness hypothesis claim random practice facilitates learning because of the opportunity to compare and contrast different memories being encoded during skill acquisition. Following each random trial, the learner processes detailed representations of the task, which forms more elaborate and distinctive memories (Lee \& Simon, 2004). Comparisons of successive elaborate memories may decrease 
overall speed and accuracy during training; however, the resultant encoded memories are rich in detail, which distinguishes them from one another in memory. This distinction makes memory retrieval easier and more efficient for the learner during retention and transfer tasks (Lee \& Simon, 2004).

Proponents of the forgetting-reconstruction hypothesis, on the other hand, postulate different memory processing occurs during training. Random practice results in "forgetting" previous tasks just practiced so that new memories can be reconstructed and encoded. "Forgetting" in this context refers to a lack of cognitive processing capability available to encode all the successive tasks being trained (Lee \& Simon, 2004), whereas "reconstruction" refers to the utilization of previously trained patterns from long-term memory or to recreating the whole pattern anew (Lee \& Simon, 2004). Early in learning, motor patterns are not directly encoded into longterm memory; thus, participants are required to reconstruct motor patterns during skill acquisition for later consolidation during the retention stage of learning. Practice schedule results in different patterns of reconstruction: 1) limited reconstruction is required for blocked practice as only a single motor pattern is rehearsed and 2) multiple reconstruction attempts are required for random practice where multiple patterns of movement are practiced. The process of reconstruction is thought to alter the effectiveness of the memories being encoded and result in enhanced performance during retention and transfer tasks (Lee \& Simon, 2004). It seems plausible that both the elaborationdistinctiveness view and the forgetting-reconstruction view may contribute to the CI effect; while people are constructing a new pattern, they can also be comparing and contrasting to previous patterns (Lee \& Simon, 2004). While these hypotheses intend to explain how the CI effect impacts memory processing, they do not detail which variables are responsible for creating this effect. 
As previously stated, there are many variables other than practice schedule that facilitate the CI effect (Battig, 1966; Landin et al., 2003; Magill \& Hall, 1990). These specific variables may include levels of expertise (Brady, 1998; Hall et al., 1994), environment (e.g., lab- versus naturallearning; Brady, 1998), verbal rehearsal (Wright et al., 1992), type of task (e.g., speech versus typing; Kaipa, 2013), and similarity between tasks (Battig, 1979 per Timothy D. Lee et al., 1992). While differences in practice schedules have been studied thoroughly in relation to the CI effect, similarity as an influencing factor has been given much less attention (Shewokis, Del Rey, \& Simpson, 1998).

\section{SIMILARITY}

Historically, similarity between two motor tasks has been important for the transfer stage of skill acquisition (Goode \& Magill, 1986; Hall et al., 1994; Travlos, 2010; Wood \& Ging, 1991). Similarity may be defined in many different ways, including physical characteristics of a movement (e.g., Landin et al., 2003; Simon \& Bjork, 2002; Tremblay, Houle, \& Ostry, 2008) or shared cognitive processes (Baddeley, 1979; Horak, 1992). For example, similarity has been defined by the type of movement executed (Hebert, Landin, \& Solmon, 1996; Landin et al., 2003; Tremblay et al., 2008), relative timing of movements (Lee et al., 1992), visual models of movement (Simon \& Bjork, 2002), and complexity of articulating words (Bislick et al., 2012). Thus, it is not clear which aspects of motor behaviors actually need to be similar to facilitate learning (Meigh, 2014).

An association between similarity and the CI effect is noted in the skill acquisition literature although it is unclear whether similarity induces or hinders contextual interference. In Battig's original definition of the CI effect, he proposed that very similar stimuli would create more contextual interference during practice resulting in enhanced transfer performance (Battig, 
1979 per Timothy D. Lee et al., 1992). Several studies in the motor limb literature align with Battig's hypothesis, where training similar motor tasks enhanced the effects of random practice, whereas training dissimilar motor tasks eliminated any effect of practice schedule (e.g., Boutin \& Blandin, 2010; Wood \& Ging, 1991; Young, Cohen, \& Husak, 1993) Accordingly, similarity between motor tasks seems to be the influencing factor in producing a CI effect during learning regardless of practice schedule. However, other motor learning studies suggest more mixed results. Kruisselbrink and Van Gyn (2011) examined the role of practice schedules (blocked versus random) and distractors between trials (similar versus dissimilar). These authors report the similarity of the distractors was the factor influencing the contextual interference effect as long as a practice schedule was used. The type of practice schedule did not matter as both blocked and random practice produced the same learning results when paired with similar distractors (Kruisselbrink \& Van Gyn, 2011). However, dissimilar stimuli paired with random practice resulted in the best performance in all stages of motor learning (acquisition, retention, and transfer; Kruisselbrink \& Van Gyn, 2011).

Despite the above evidence there is also empirical support in the limb literature to suggest similarity may decrease overall transfer performance in, for example, pushing a series of buttons, switches, and piano keys (for a review see Brady, 1998; Glenberg, 1977; Lee et al., 1992; Wifall, McMurray, \& Hazeltine, 2014). For example, Wifall et al., 2014 documented that participants who practiced playing piano chords that shared several keys (similar stimuli) required more time to play compared to those participants who practiced dissimilar piano chords. CI effects may be observed with both similar and dissimilar stimuli (e.g., Chung, 1995); however, a stronger CI effect has been found when utilizing dissimilar stimuli (Brady, 1998; Chung, 1995; Kruisselbrink \& Van Gyn, 2011). Dissimilar stimuli may also interact with practice schedule during motor learning. 
Lee, Wulf, and Schmidt (1992) reported practice schedule only induced a CI effect when dissimilar movement patterns were practiced during the acquisition stage of learning.

Of the evidence presented, CI effects due to dissimilar stimuli more acutely align with the hypotheses put forth to explain CI effects following random practice. Similar stimuli lack distinctive features, which may result in a limited number of features being encoded into memory during skill acquisition (Kruisselbrink \& Van Gyn, 2011). This would decrease learners' ability to retrieve memories efficiently and/or reconstruct stimuli easily during retention and transfer tasks (Kruisselbrink \& Van Gyn, 2011; Lee \& Simon, 2004). It has also been suggested that dissimilarity may only influence the amount of interference during skill acquisition but not the underlying memory representation (Brady, 1998); thus, dissimilarity between stimuli may only be one of several variables (including practice schedule) to induce a CI effect. As noted previously, it is difficult to discern the role of similarity in regards to practice schedule. Similar stimuli may increase performance during acquisition or retention stages of learning, while dissimilar stimuli may increase performance during transfer stages regardless of a random or blocked practice schedule (Magill \& Hall, 1990; Simon \& Bjork, 2002).

In summary, the influence of similarity (i.e., similar or dissimilar characteristics of movement) on motor learning appears evident, though the exact nature of how this variable influences various stages of skill acquisition or other variables of motor learning (e.g., practice schedule) is still unclear. Thus, it is of great interest to determine how this variable modulates the CI effect (Bortoli, Robazza, Durigon, \& Carra, 1992; Goode \& Magill, 1986; Hall et al., 1994; Hebert et al., 1996; Horak, 1992; Travlos, 2010; Wood \& Ging, 1991) to better optimize motor learning outcomes. More specifically, understanding how similarity of motor tasks modulate the CI effect may aid our understanding of speech motor learning. 


\section{STUDY PURPOSE}

Understanding which variables modulate the CI effect is important for our theoretical understanding of speech motor control, as well as our ability to translate this knowledge into clinical outcomes. Practice schedule and similarity have not yet been systematically evaluated together within the speech motor control literature. When the CI effect was originally proposed, the main facilitator of this effect was the concept of intratask interference, where similarity between novel tasks created interference (Battig, 1966, 1979; Shewokis et al., 1998). It was only later that researchers discovered practice schedule variations and lost sight of similarity as an influencing factor of the CI effect (Battig, 1979; Shewokis et al., 1998). With the varying evidence reviewed above, it is difficult to say exactly how similarity modulates the CI effect during motor learning. This is even more difficult to determine in regards to speech motor learning as only practice schedule has been investigated as a variable influencing contextual interference effects. Several studies have demonstrated a CI effect with practice schedule in clinical populations (e.g., Austermann-Hula, Robin, Maas, Ballard, \& Schmidt, 2008; Ballard, Robin, Knock, \& Schmidt, 1999; Knock, Ballard, Robin, \& Schmidt, 2000). Additionally, separate studies have evaluated the effect of similarity on transfer performance in speech production. For instance, phoneme similarity influences participants ability to learn nonwords (Meigh, 2017). Further investigating these variables together would provide insight into how the benefits of random practice may be influenced by other speech variables (e.g., phoneme similarity) in speech motor learning. Therefore, the specific aim of this study is to determine the extent to which learning nonwords is influenced by phonemic similarity under random practice conditions.

The first question this study aims to answer is whether there is a difference in accurately producing nonwords when phonemic contexts have high versus low similarity. The motor learning literature suggests similarity between stimuli or motor movements is essential to enhanced 
performance during the various stages of motor learning (Boutin \& Blandin, 2010; Magill \& Hall, 1990; Simon \& Bjork, 2002; Wood \& Ging, 1991; Wright et al., 1992; Young et al., 1993). Therefore, it is hypothesized trained stimuli sharing the same phonemes will be produced more accurately than trained stimuli that have few phonemes in common regardless of stage of skill acquisition.

The second question that this study aims to answer is whether there is a difference in accurately producing nonwords varying in phonemic similarity across different stages of motor learning. Using a well-established variable of the CI effect (random practice), it is hypothesized that differences in accuracy will be observed between similar and dissimilar stimuli during different stages of skill acquisition. Specifically, it is hypothesized that trained stimuli sharing the same phonemes will be produced more accurately during the acquisition and retention stage of the experiment than trained stimuli with different phonemes. It has been repeatedly demonstrated that similar stimuli are easier to execute compared to dissimilar stimuli during practice as the similar stimuli are produced with higher levels of accuracy (Battig, 1979; Lee et al., 1992; Magill \& Hall, 1990; Simon \& Bjork, 2002). It is also hypothesized that transfer stimuli with different phonemes will be produced more accurately during the transfer stage of the experiment than transfer stimuli with similar phonemes. Dissimilar stimuli are anticipated to be more difficult to execute during practice than similar stimuli; thus, an increase in contextual interference should aide transfer performance (Boutin \& Blandin, 2010; Brady, 1998; Chung, 1995; Glenberg, 1977; Jarus et al., 1997; Kruisselbrink \& Van Gyn, 2011; Lee et al., 1992; Magill \& Hall, 1990; Simon \& Bjork, 2002; Travlos, 2010; Wifall et al., 2014). Using the CI effect as a framework, it would be expected that nonwords with dissimilar phonemes will be articulated with increased accuracy during the 
transfer stage of skill acquisition than nonwords with similar phonemes (Glenberg, 1977 per Kruisselbrink \& Van Gyn, 2011).

\section{METHODS}

\section{PARTICIPANTS}

Twenty-nine participants between the ages of 18-35 were recruited to participate in this study. The proposed sample size for this study is based on the following parameters input into the statistical power analysis program $\mathrm{G}^{*}$ Power: effect size $=.26 ; \alpha=.05$, power $=.80$. All participants were prescreened for language and education prior to coming into the Speech Motor Control Lab. Specifically, participants were required to be monolingual English speakers as defined by a custom-designed language questionnaire (Appendix A) and hold a high school diploma (or equivalent). If participants met these initial criteria, they were then screened in the lab for normal speech and hearing skills.

Screening for normal speech included an oral-facial sensory-motor exam where the following parameters were within normal limits (Duffy, 1995): facial symmetry; lingual protrusion and retraction; labial protrusion, retraction, and closure; elevation and depression of the mandible; and symmetrical movement of the velum. All participants were required to produce a prolonged vowel and diadochokinetic rates within one standard deviation of the minimum normative values (Duffy, 1995), as well as have no articulation errors or disfluent speech on the Test of Minimal Articulation Competence Screening tests (Secord, 1981). Conversational speech during screening procedures was also monitored for speech errors and disfluent speech. Screening for normal hearing included being able to detect pure tones at $500 \mathrm{~Hz}, 1000 \mathrm{~Hz}, 2000 \mathrm{~Hz}$, and $4000 \mathrm{~Hz}$ in at least one ear at $40 \mathrm{~dB}$ (American Speech-Language-Hearing Association, 1990). All participants were required to correctly repeat the Northwestern University Test \#6 words (NU-6; Tillman \& 
Carhart, 1966) with no more than one mistake (45/46 on list $2 \mathrm{~A}$ male speaker recordings). If abnormal speech, language, or hearing were recognized in a participant during the screening, he or she was dismissed from the study and referred to the West Virginia University Speech and Hearing Center for a complete speech and language and/or audiological evaluation. The Memory for Digit and Nonword Repetition subtests from the Comprehensive Test of Phonological Processing $-2^{\text {nd }}$ edition (Wagner, Torgesen, Rashotte, \& Pearson, 2013) were also administered prior to the experimental protocol to evaluate each participant's phonological memory. Participants performed in the average range based on scaled score on the CTOPP-2 Memory Digit Span Test $(M(S D)=10.04(1.59))$ and the Nonword Repetition Test $(M(S D)=9.44(2.24))$. These measures were not used to exclude participants from the study but were used to inform data analysis if outlier data were present.

Participant recruitment took place using IRB-approved fliers posted in public spaces around West Virginia University, IRB-approved ads posted to the Speech Motor Control Lab Facebook page, and IRB-approved email blasts through different West Virginia University colleges (e.g., College of Education and Human Services). Additional recruitment occurred through the West Virginia University psychology pool (SONA) with approval from the Psychology Department. All study procedures were conducted in the WVU Speech Motor Control Laboratory by the primary investigator or a trained IRB-approved investigator.

Participants interested in this study contacted the PI via the Speech Motor Control lab email account regarding their interest in the study. At that time, a pre-screening language questionnaire (see Appendix A) was administered. Participants who passed the pre-screening were scheduled for an experimental session, and those who did not were thanked for their time. During a scheduled experimental session, written consent was obtained according to procedures outlined by the West 
Virginia University's Institutional Review Board. Following consent, participants completed the screening procedure to determine eligibility (as outlined above). All screening procedures took less than 30 minutes to complete, and participants who passed the screening protocol were compensated with a $\$ 15$ gift card following their completion of this study.

\section{EXPERIMENTAL SETUP}

The experimental procedure consisted of a nonword repetition training task followed by a nonword repetition generalization task for each set of stimuli described below. After the screening, participants were seated in a comfortable chair, and a dynamic headset unidirectional microphone (SHURE WH20XLR) was placed approximately one-inch mouth-to-microphone distance. The microphone was connected to a digital voice recorder (Olympus DM-901), which was centered on the table approximately 6 inches from the participant to record all experimental tasks. A 64-bit Dell Latitude 3340 laptop utilizing Windows 7 operating system was used to run the experimental software, E-Prime (Schneider, Eschman, \& Zuccolotto, 2002). Stereo speakers (Bose Companion 2 Series 3) were centered on the table approximately 15 inches in front of the participant.

\section{STIMULI}

Stimuli from Meigh (2017) were used for this experiment and divided into two categories: 1) similar vs. dissimilar and 2) trained vs. untrained (See Appendix B). Each category had 20 stimuli resulting in a total of 40 stimuli. All stimuli consisted of seven phonemes, three syllables $(\mathrm{CV}|\mathrm{CV}| \mathrm{CVC})$ with syllable stress occurring in the first or second syllable position, and low frequency combinations of consonant gestures (i.e., the movements between phonemes). Of the twenty similar stimuli, ten stimuli were matched with an identical nonword that varied only in the order of the first and second syllable (e.g., /tee|nce|rok/ and /nce|te|rok/). Thus, the number of different phonemes for a given pair of stimuli was minimized to four phonemes, and of these four 
phonemes the order of phonemes within a given syllable were the same. Dissimilar stimuli were not matched on any phonemic or syllabic property and varied by the phonemes used, as well as the phoneme order within a syllable unit (e.g., /gI $\left|\mathrm{b}_{\mathrm{r}}\right| \mathrm{Jr}_{\mathrm{r}} /$ and $/ \int \mathrm{J}|\mathrm{d} z \partial| \mathrm{z} \mathrm{d} /$ ). Dissimilar nonwords pairs typically varied by 5-7 phonemes. Each similar and dissimilar stimuli set were divided into two groups, trained and transfer stimuli, for a total of 10 stimuli in each of the following groups: Similar-Trained, Dissimilar-Trained, Similar-Transfer, Dissimilar-Transfer. Trained stimuli were practiced during the nonword repetition-training portion of the experiment, and both trained and untrained stimuli were used during the nonword repetition generalization task.

\section{NONWORD REPETITION TRAINING}

During training, participants heard a nonword and repeated it into a headset microphone. Participants were randomly assigned to practice Similar-Trained stimuli or Dissimilar-Trained stimuli to initiate training (Figure 1). Participants practiced repeating these initial stimuli sets for 100 repetitions separated into 10 blocks (10 stimuli each). This number of repetitions has been successful in enhancing overall motor learning in similar experimental protocols (e.g., Almelaifi, 2013; Meigh, 2017; Meigh \& Shaiman, 2010). Participants were also provided with two types of feedback during training. During training sets, verbal encouragement was provided by the examiner at pseudo-random intervals. The examiner also documented any misarticulated nonwords during training by pressing a key on the laptop to initiate a summary feedback procedure in Eprime following all trials within a block. During summary feedback, Eprime re-played the original recording of the mispronounced nonwords through the speaker. This type of feedback has been successfully used in studies of speech and nonspeech practice to enhance overall accuracy (e.g., S. G. Adams, Page, \& Jog, 2002; Maas et al., 2008). No other feedback regarding articulation accuracy was provided during training (e.g., by the examiner). 


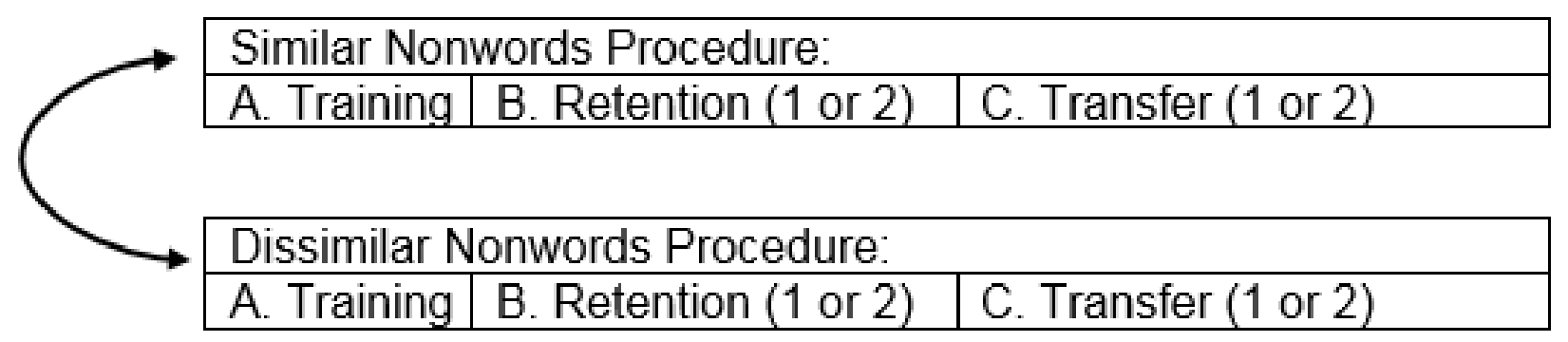

FIGURE 1: EXPERIMENTAL PROCEDURE

Following ten blocks of training, participants completed the corresponding retention and transfer blocks depending on which set of stimuli they were practicing (Figure 1; described in the Nonword Repetition Generalization Section below). Once the first procedure (i.e., training, retention, and transfer) was completed, the participants went on to complete the other stimuli procedure (Figure 1). The order of training blocks was counterbalanced across participants in an effort to avoid an order effect of the stimuli presentation. Additionally, all stimuli within a given training block were randomized to ensure a random practice schedule. A random practice schedule was predicted to increase overall learning outcomes in this study, and produce a contextual interference effect based on practice schedule alone (e.g., Battig, 1979; Maas et al., 2008; J. B. Shea \& Morgan, 1979). During training, participants were presented with multiple breaks to prevent fatigue.

\section{NONWORD REPETITION GENERALIZATION}

Following training, participants repeated nonwords into a headset microphone in two different generalization tasks aimed at evaluating the last two stages of skill acquisition - retention and transfer. First, participants repeated trained nonwords (Similar-Trained or Dissimilar-Trained stimuli) to evaluate overall learning (retention task). Second, participants repeated untrained nonwords (Untrained-Similar or Untrained-Dissimilar stimuli) to evaluate transfer to novel stimuli 
(transfer task). This protocol was nearly identical to the nonword repetition-training task except participants did not receive feedback on their performance. All stimuli were randomized within each task, and each generalization task was counterbalanced across participants to avoid an order effect (Table 1).

TABLE 1: COUNTERBALANCING ACROSS TRAINING AND GENERALIZATION TASKS

\begin{tabular}{|l|l|l|l|l|l|l|}
\hline Subjects & Training 1 & \multicolumn{2}{|c|}{ Generalization 1 } & Training 2 & \multicolumn{2}{c|}{ Generalization 2 } \\
\hline Ss 1 & $\begin{array}{l}\text { Similar- } \\
\text { Trained }\end{array}$ & $\begin{array}{l}\text { Similar } \\
\text { Retention \#1 }\end{array}$ & $\begin{array}{l}\text { Similar } \\
\text { Transfer \#1 }\end{array}$ & $\begin{array}{l}\text { Dissimilar- } \\
\text { Trained }\end{array}$ & $\begin{array}{l}\text { Dissimilar } \\
\text { Retention \#1 }\end{array}$ & $\begin{array}{l}\text { Dissimilar } \\
\text { Transfer \#1 }\end{array}$ \\
\hline Ss 2 & $\begin{array}{l}\text { Similar- } \\
\text { Trained }\end{array}$ & $\begin{array}{l}\text { Similar } \\
\text { Retention \#2 }\end{array}$ & $\begin{array}{l}\text { Similar } \\
\text { Transfer \#2 }\end{array}$ & $\begin{array}{l}\text { Dissimilar- } \\
\text { Trained }\end{array}$ & $\begin{array}{l}\text { Dissimilar } \\
\text { Retention \#2 }\end{array}$ & $\begin{array}{l}\text { Dissimilar } \\
\text { Transfer \#2 }\end{array}$ \\
\hline Ss 3 & Dissimilar- & Dissimilar & Dissimilar & Similar- & Similar & Similar \\
& Trained & Retention \#1 & Transfer \#1 & Trained & Retention \#1 & Transfer \#1 \\
\hline Ss 4 & Dissimilar- & Dissimilar & Dissimilar & Similar- & Similar & Similar \\
& Trained & Retention \#2 & Transfer \#2 & Trained & Retention \#2 & Transfer \#2 \\
\hline
\end{tabular}

\section{DATA PREPARATION}

Data for twenty-five participants were analyzed for this study. Attrition was secondary to three participants failing one or more portions of the screening procedure, and equipment failure during one participant's session._Nonword repetitions from the retention and transfer tasks were individually scored by two listeners trained in phonetic transcription using the procedures described by Dollaghan and Campbell (1998). Specifically, each phoneme within a stimulus was marked as correct or incorrect as compared to the target phoneme. Omissions and substitutions of phonemes were considered incorrect; however, distortions were marked as correct and additions were not scored. Any discrepancies of scores were resolved by a third, blinded rater trained in phonetic transcription, and a percent phonemes correct (PPC) calculation was completed for the entire nonword. 


\section{HYPOTHESES}

1. Does accuracy in producing nonwords, as measured by PPC, increase for stimuli with phonemic similarity compared to stimuli with phonemic dissimilarity regardless of skill stage? Similarity between motor movements has been reported to enhance performance across various stages of skill acquisition (Boutin \& Blandin, 2010; Magill \& Hall, 1990; Wood \& Ging, 1991; Young et al., 1993). If phonemic accuracy always improves when similar phonemes are practiced then a contextual interference effect will not be present (Figure 2).

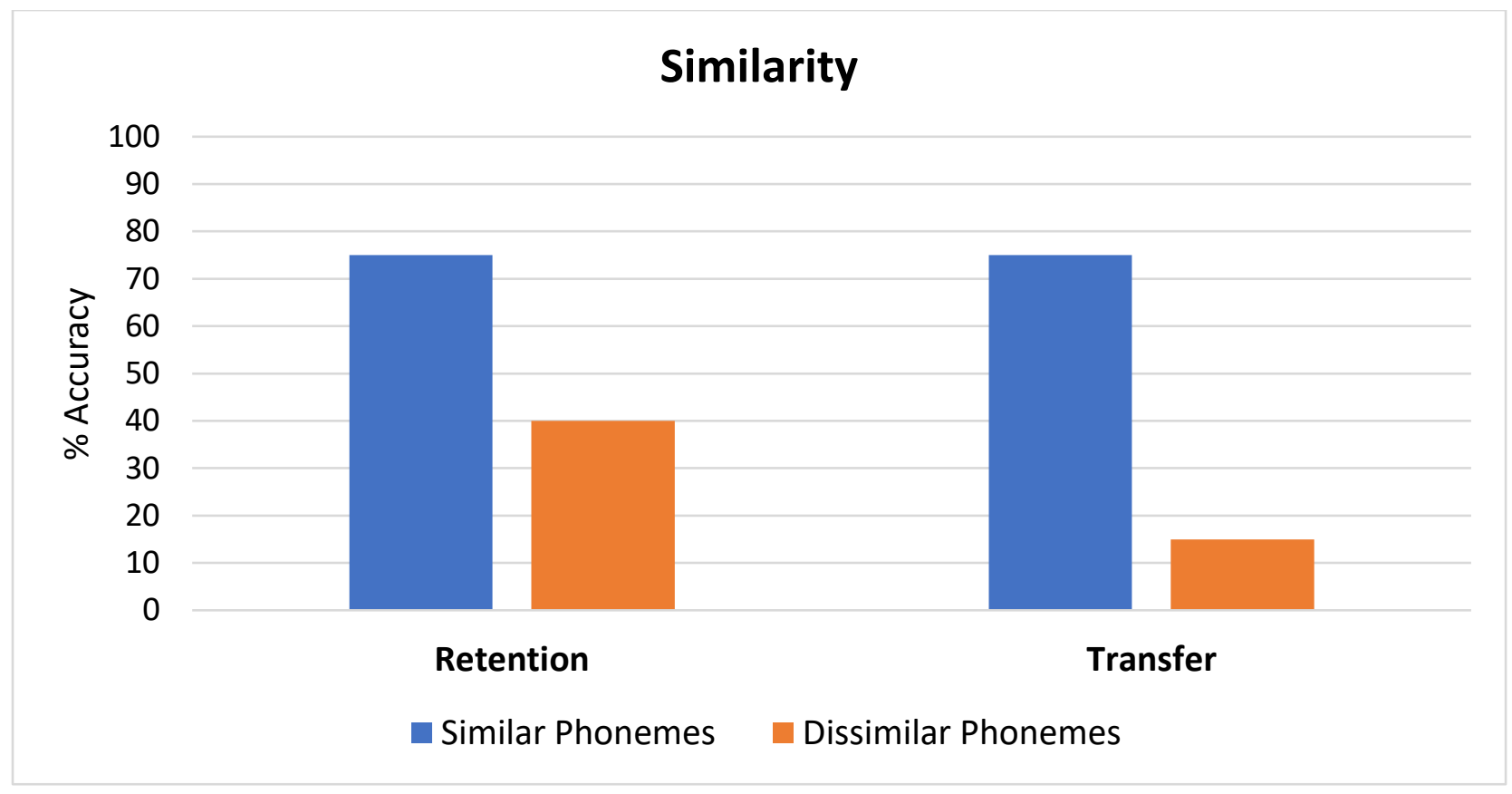

Figure 2: Depiction of hypothesis 1 demonstrating accuracy of similar vs. dissimilar stimuli across retention and transfer tasks with similarity of stimuli present across all skill stages

2. Does accuracy in producing nonwords (i.e., PPC) vary by skill stage and phonemic similarity? It is predicted that PPC will vary by skill stage, such that increased PPC values will be observed for similar stimuli during the retention task, whereas increased PPC values will be observed for dissimilar stimuli during the transfer task (Figure 3). This pattern of results would indicate 
a contextual interference effect secondary to phoneme similarity (Battig, 1979; Maas et al., 2008; Shea \& Morgan, 1979).

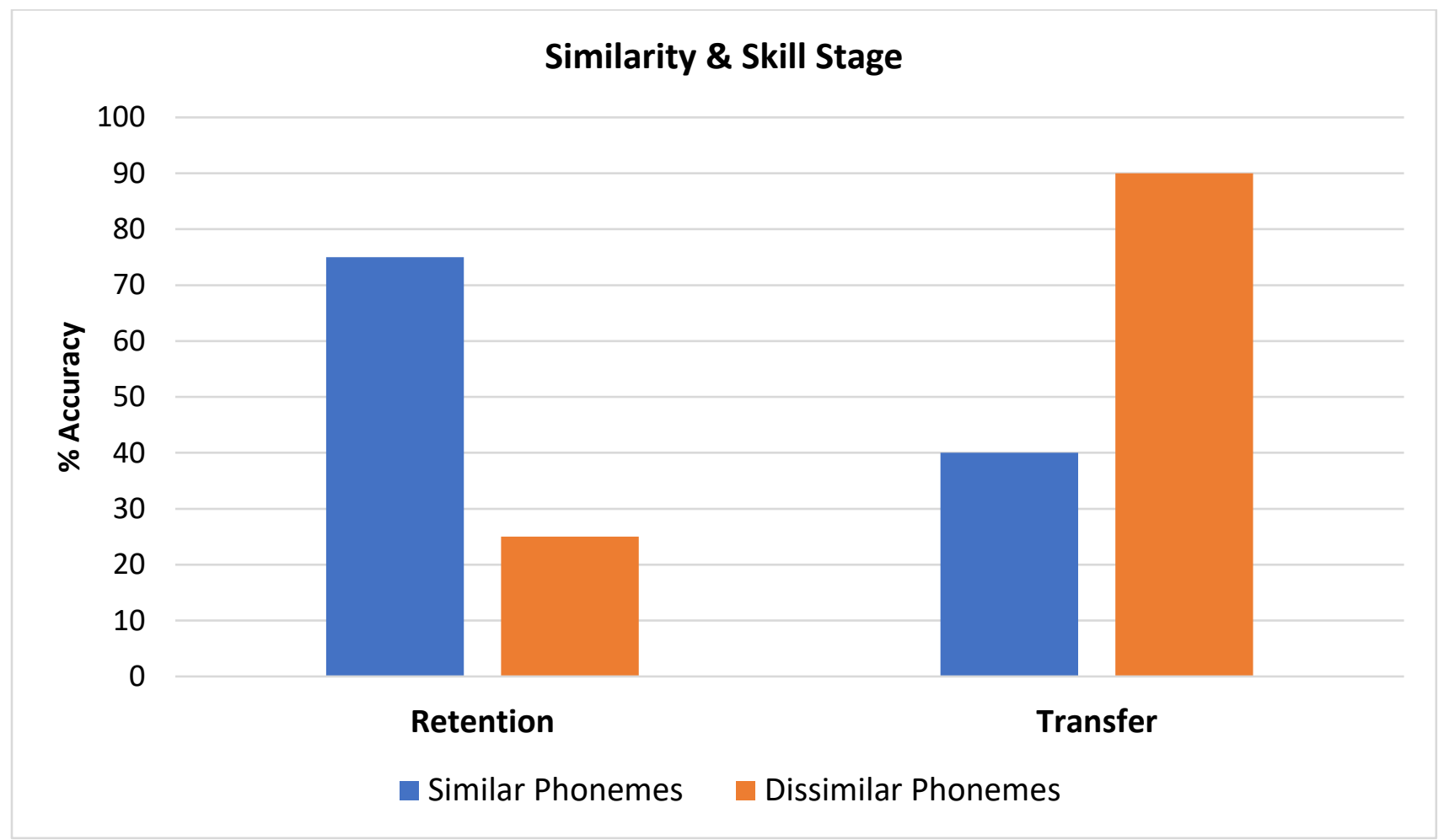

Figure 3: Depiction of hypothesis 2 demonstrating accuracy of similar vs. dissimilar stimuli across retention and transfer tasks with an interaction effect present between stimuli similarity and skill stage 


\section{RESULTS}

A Friedman test was run to determine if there were differences in the percentage of phonemes correctly produced (PPC; Dollaghan, 1998) in similar and dissimilar nonwords produced during different stages of skill acquisition. Pairwise comparisons were performed (SPSS, 2012) with a Bonferroni correction for multiple comparisons. PPC was statistically significant across stimuli and stage of motor learning, $\chi^{2}(3)=38.811, p<.0005$ (Figure 4). Post hoc analysis revealed statistically significant differences in PPC when examining nonword similarity across skill stage (Hypothesis 1) and within skill stage (Hypothesis 2).

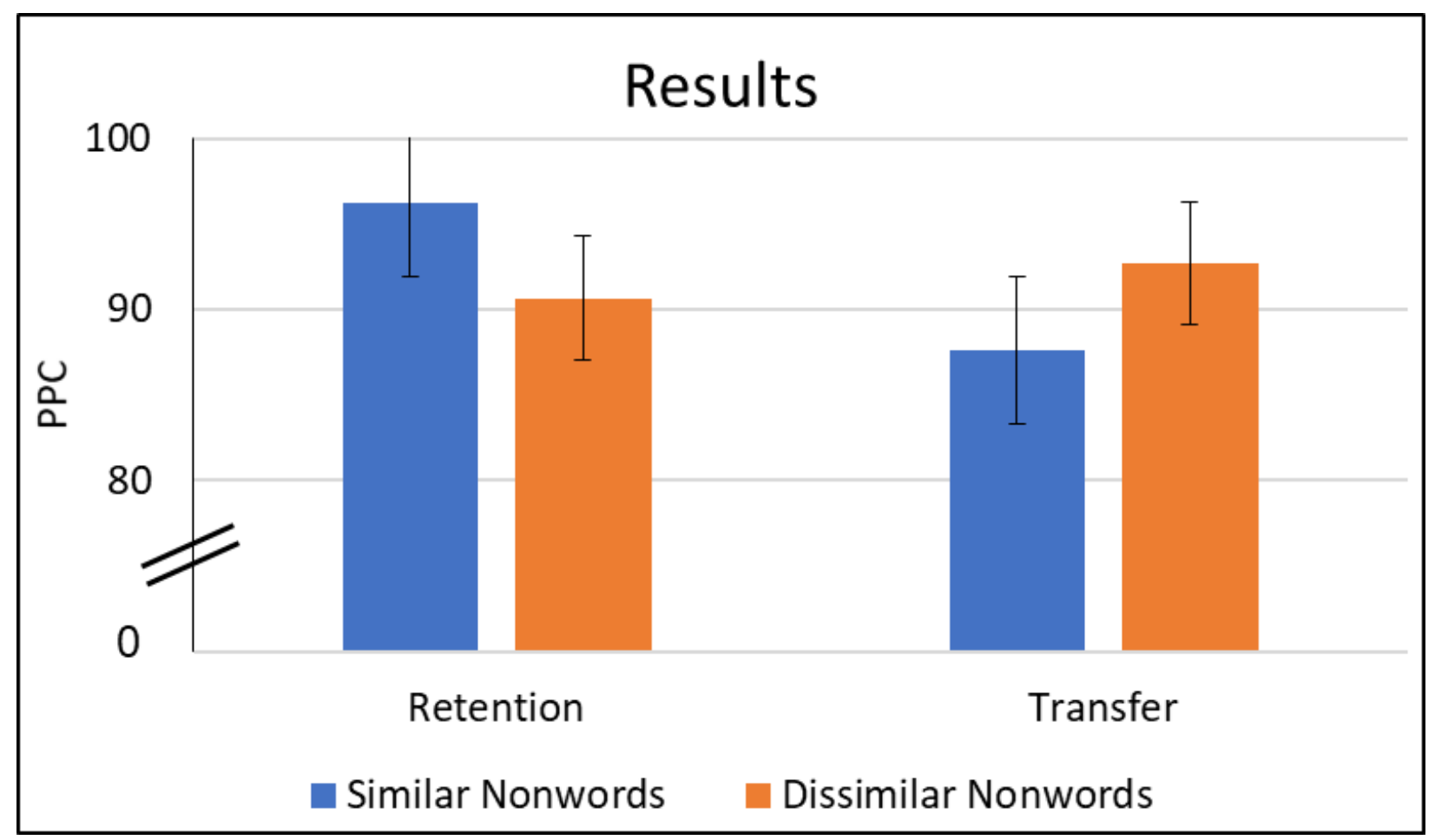

Figure 4: PPC values across stimuli type and stage

\section{ACROSS SKILL STAGES}

This comparison contrasted the same type of stimuli across retention and transfer stages (e.g., similar-retention and similar-transfer). There was a statistically significant increase in PPC values when participants produced similar nonwords during the retention stage $(M d n=97.14)$ compared 
to the transfer stage $(M d n=90.00)$ of motor learning $(p<0.0005)$. However, there was no significant difference in PPC values when dissimilar nonwords were produced regardless of motor learning stage (retention $M d n=91.43$; $\operatorname{transfer} M d n=92.86 ; p=.256$ ). .

\section{WITHIN SKILL STAGES}

This comparison contrasted different types of stimuli across the same skill stage (e.g., similar retention vs. dissimilar retention). Post-hoc analysis revealed statistically significant decrease in PPC between similar $(M d n=97.14)$ and dissimilar $(M d n=91.43)$ stimuli in the retention phase of the experiment $(p<0.0005)$. There was also statistically significant increase in PPC values when participants produced dissimilar $(M d n=92.86)$ versus similar $(M d n=90.00)$ nonwords during the transfer state $(p=.011)$. 


\section{DISCUSSION}

A contextual interference (CI) effect was hypothesized to be modulated by dissimilarity; specifically, nonsense words constructed with dissimilar phonemes. Nonwords with dissimilar phonemes were hypothesized to be more difficult to articulate during the retention task when compared with nonwords with similar phonemes. However, during the transfer task (i.e., when encountering novel nonwords), it was hypothesized that participants would produce more phonemes correctly with nonwords with dissimilar phonemes. The results of this study suggest that phoneme dissimilarity is a variable capable of modulating a CI effect, and that phoneme similarity (i.e., nonwords composed of highly similar phonemes) may be detrimental to overall motor learning.

The results of this study demonstrate significant differences between similar and dissimilar nonsense words across and within the retention and transfer stages of motor learning. As noted earlier, differences in accuracy across retention and transfer stages provides insight into the role of phonemic similarity during motor learning. Participants produced similar nonsense words with significantly greater accuracy during the retention stage than the transfer stage of this experiment. However, there was no significant difference found in accuracy when producing dissimilar nonsense words during retention and transfer stages. These results suggest that similarity may not always be beneficial to motor learning, which opposes traditional theories regarding similarity as always being beneficial for long-term learning (i.e., generalization; Goode \& Magill, 1986). It also suggests that practicing with dissimilar stimuli or movement patterns will not result in negative learning outcomes as previously thought (Magill \& Hall, 1990). Indeed, these results suggest overall accuracy in producing dissimilar stimuli as good, and this pattern of accuracy was

maintained with novel stimuli (i.e., transfer stage of learning). This contrasts with the overall learning pattern observed with similar stimuli, where accuracy decreased (below that of the 
dissimilar stimuli) when novel stimuli were introduced. In summary, the pattern of learning produced in this study does not align with traditional theories of similarity where similar movement patterns result in better learning outcomes. Instead, the results of this study suggest phonemic similarity may be a variable capable of modulating a CI effect.

Differences in accuracy between stimuli types during the retention and transfer stages of learning were present in this study. As noted in the introduction, similarity has been hypothesized to be a variable involved in producing CI effects. However, it was unclear whether the properties of similar or dissimilar stimuli were the driving factor in producing this effect. I hypothesized that practicing dissimilar stimuli would produce the most interference in much the same way as random practice, i.e., practicing a variety of movement patterns would facilitate encoding flexible memories (Jarus, Wughalter, \& Gianutsos, 1997; Lee et al., 1992). These results provide support for this conclusion; however, the high level of accuracy observed following practice with dissimilar nonwords was surprising. Based on these data alone, including similar nonsense words in training did not provide any benefit to overall motor learning. In fact, the differences in accuracy between similar and dissimilar nonwords following the retention task (see Table 2) suggest using only dissimilar stimuli should be warranted in the future - all the benefit of generalization without the decrement in learning during the retention phase.

Table 2: Percent Phonemes Correct Mean and Standard Deviation (SD) of each Stimuli Type across stages of skill acquisition

\begin{tabular}{|l|c|c|}
\hline & Retention Mean (SD) & Transfer Mean (SD) \\
\hline Similar Nonwords & $96.21(3.08)$ & $87.58(7.8)$ \\
\hline Dissimilar Nonwords & $90.66(5.05)$ & $92.69(4.26)$ \\
\hline
\end{tabular}


Intuitively, it would seem that practicing dissimilar motor tasks would be more challenging than practicing similar motor tasks, hence the resultant $\mathrm{CI}$ effect modulated by phoneme dissimilarity. However, the results of this study align with the elaboration-distinctiveness and the forgetting-reconstruction hypotheses (Boutin \& Blandin, 2010; Maas et al., 2008; Simon \& Bjork, 2002). Decreased accuracy articulating nonwords with similar phonemes during the transfer stage of motor learning has been attributed to the learner having trouble discriminating between the similar memory representations acquired during the previous stages of skill acquisition (Kruisselbrink \& Van Gyn, 2011). Thus, during the acquisition phase, the learner may not be able to discriminate the unique features between similar stimuli (either through elaboration or reconstruction) resulting in encoded memory representations that lack distinctive features. During later stages of motor learning (retention and transfer), retrieving memory representations from long-term memory becomes difficult resulting in lower accuracy and speed (Kruisselbrink \& Van Gyn, 2011). On the other hand, practicing nonwords with dissimilar phonemes encoded very distinctive memory representations during acquisition, which allows for more efficient and accurate memory retrieval during the retention and transfer stages of motor learning (Kruisselbrink \& Van Gyn, 2011; for a full review see Magill \& Hall, 1990).

In summary, the results of this study indicate that practicing nonwords with mostly dissimilar phonemes induces the best overall motor learning outcomes (i.e., increased production of accurate phonemes). Although similarity of movement patterns has traditionally been heralded as a main predictor of motor learning success, these results implicate other potential factors. Defining similarity (or dissimilarity) has been a challenge in motor theory (c.f., physical properties of movement, underlying cognitive processes). However, speech is unique compared with other movement patterns in that motor and linguistic variables influence overall motor execution. There 
may be linguistic factors not traditionally associated with motor behaviors, such as phoneme similarity, that may influence motor learning. The results of this study suggest linguistic factors, namely phonemic dissimilarity, enhance motor learning by increasing overall interference during learning. This is at odds with traditional views of similarity that suggest aligning similar properties of motor behaviors will result over great learning outcomes. Although this finding is novel, there are several limitations that should be considered.

First, all of the motor learning stages were completed consecutively in one session. It could be argued that the retention and transfer tasks in this experiment only evaluated performance and not true learning, i.e., consolidation of memories into long-term memory, which is often tested several hours, days, or weeks from training (e.g., Battig, 1979; Schmidt \& Lee, 2005). During the experiment there was no specified time frame between motor learning stages. As noted previously in the introduction, retention tasks may be short-term or long-term (Battig, 1979) and a short-term retention task was used in this study. A long-term retention task was not implemented due to limited funding and the potential for subject attrition, which has been noted in other studies. Meigh and Shaiman (2010) utilized a similar motor learning paradigm using a 2-day design where training occurred on the first day followed by a second day where retention and transfer tasks were administered. Subject attrition for this study was high with subjects not completing the second day of the experiment without additional payments. Replication of this study should include a multiday motor learning paradigm to evaluate if the contextual inference effect noted with short-term retention and transfer is also observed.

Another limitation to this study is that the stimuli set was taken from (Meigh, 2017) instead of the author creating new nonwords. Although these stimuli were validated to be similar and/or dissimilar from one another based on phonemic properties, there were limited stimuli that could 
be used for training, retention, and transfer tasks. As noted in Appendix B, each training set had ten nonwords (which were also used in the retention task) and each transfer task had ten nonwords. Creating a new set of stimuli would have allowed for more of each type of stimuli, which also would have made a multi-day experimental design more feasible. However, for an initial evaluation of the contextual interference effect in speech motor learning, using validated stimuli based on the independent variable in this study (i.e., similarity of phonemes within a nonword) provided more control than the creation of new stimuli. Future studies may want to replicate and extend this study with new nonwords that may vary other properties of phonemes, e.g., manner of articulation.

A third possible limitation to this study was the type of feedback provided during training. When the participants incorrectly articulated a nonsense word, summary feedback was provided in the form of an audible repetition of the nonsense word. Participants were not provided with any other feedback regarding their misarticulation, e.g., articulatory placement. Other forms of summary feedback, e.g., as knowledge of performance, may have been more beneficial. Currently, there is no systematic evidence in the speech motor literature that favors one type of feedback over the other at this point in time (Maas et al., 2008). However, the overall high accuracy across stimuli types and stage of motor learning (i.e., above $85 \%$ accuracy) suggests participants were able to utilize the nonword repetitions successfully to facilitate performance. Future studies should consider analyzing different types of feedback to better understand how these variables affect speech motor learning.

An additional limitation of this study was the use of a single dependent variable (percentage of phonemes correct) in only two out of three stages of motor learning (retention and transfer); no analyses were conducted analyzing participants' progress during training. The focus on the last 
two stages of motor learning are consistent with experimental designs evaluating the contextual interference effect (for a review see Magill \& Hall, 1990). As noted previously, the overall accuracy in these stages for this study was above $85 \%$, which suggests learning did occur during training. However, it is possible individual participants varied in their learning and these differences were masked by the overall mean performance. Although this study controlled for the number of trials each participant practiced during training, future studies should include an analysis (e.g., PPC) of the skill acquisition stage of learning and evaluate individual variability across participants.

Finally, this study only looked at manipulating phoneme similarity within the context of random practice. Blocked practice was not implemented at all during this study as the reviewed literature suggested that the role of similarity had no bearing on practice schedule (e.g., Kruisselbrink \& Van Gyn, 2011) or that similarity only enhanced random practice effects (e.g., Boutin \& Blandin, 2010; Wood \& Ging, 1991; Young et al., 1993). Therefore, in order to enhance overall learning, a random practice schedule was utilized in this study. However, to truly parse out whether practice schedule needs to be paired with dissimilar stimuli to produce a contextual interference effect (e.g., Lee et al., 1992), blocked and random practice should be incorporated into future research designs.

In conclusion, future research should look at the relationship between motor learning and other linguistic factors, like phoneme similarity, which are not usually associated with motor behaviors. The results of this study suggest that practicing nonwords made up of dissimilar phonemes enhanced motor learning compared to nonwords made up of similar phonemes. Different linguistic factors which can be used to construct stimuli may also influence motor learning. After gaining a deeper understanding into exactly how these linguistic factors are 
influencing motor learning, it may be possible to shape stimuli used in therapy in such a way as to optimize speech-motor learning. 


\section{REFERENCES}

Adams, J. A. (1987). Historical review and appraisal of research on the learning, retention, and transfer of human motor skills. Psychological Bulletin, 101(1), 41-74.

Adams, S. G., \& Page, A. D. (2000). Effects of selected practice sand feedback variables on speech motor learning. Journal of Medical Speech-Language Pathology, 8, 215-220.

Adams, S. G., Page, A., \& Jog, M. (2002). Summary feedback schedules and speech motor learning in Parkinson's disease. Journal of Medical Speech-Language Pathology, 10, 215220.

Almelaifi, R. (2013). The role of "focus of attention" on the learning of non-native speech sounds: English speakers learning of mandarin Chinese tones (Dissertation). University of Pittsburgh, Pittsburgh. PA. Retrieved from http://d-scholarship.pitt.edu/16937/

American Speech-Language-Hearing Association. (1990). Guidelines for screening hearing impairment and middle-ear disorders. ASHA, 32(2), 17-24.

Austermann-Hula, S. N., Robin, D. A., Maas, E., Ballard, K. J., \& Schmidt, R. A. (2008). Effects of feedback frequency and timing on acquisition and retention of speech skills in acquired apraxia of speech. Journal of Speech, Language, and Hearing Research, 51, 1088-1113.

Baddeley, A. (1979). Transfer-appropriate processing: A critical review. In L. S. Cermak \& F. I. M. Craik (Eds.), Levels of processing in human memory. Hillsdale, NJ: Erlbaum.

Ballard, K. J., Robin, D. A., Knock, T. L., \& Schmidt, R. A. (1999). Influence of frequency of feedback and order of stimulus presentation on treatment for apraxia of speech. Presented at the Clinical Aphasiology Conference., Key West, FL.

Ballard, K. J., Wambaugh, J. L., Duffy, J. R., Layfield, C., Maas, E., Mauszycki, S., \& McNeil, M. R. (2015). Treatment for Acquired Apraxia of Speech: A Systematic Review of 
Intervention Research Between 2004 and 2012. American Journal of Speech-Language Pathology, 24(2), 316. https://doi.org/10.1044/2015_AJSLP-14-0118

Battig, W. F. (1966). Facilitation and interference. In E. A. Bilodeau (Ed.), Acquisition of skill (pp. 215-244). New York, NY: Academic Press.

Battig, W. F. (1979). The flexibility of human memory. In L. S. Lermack \& F. I. M. Craik (Eds.), Levels ofprocessing in human memory (pp. 23-44). Hillsdale, NJ: Erlbaum.

Bislick, L. P., Weir, P. C., Spencer, K., Kendall, D., \& Yorkston, K. M. (2012). Do principles of motor learning enhance retention and transfer of speech skills? A systematic review. Aphasiology, 26(5), 709-728. https://doi.org/10.1080/02687038.2012.676888

Bortoli, L., Robazza, C., Durigon, V., \& Carra, C. (1992). Effects of contextual interference on learning technical sports skills. Perceptual and Motor Skills, 75(2), 555-562.

Boutin, A., \& Blandin, Y. (2010). On the cognitive processes underlying contextual interference: Contributions of practice schedule, task similiarity and amount of practice. Human Movement Science, 29, 910-920.

Brady, F. (1998). A Theoretical and Empirical Review of the Contextual Interference Effect and the Learning of Motor Skills. Quest, 50(3), 266-293. https://doi.org/10.1080/00336297.1998.10484285

Chung, H. C. (1995). Task characteristics and contextual interference. University of Georgia.

Dollaghan, C. (1998). Spoken word recognition in children with and without specific language impairment. Applied Psycholinguistics, 19(02), 193-207.

Dollaghan, C., \& Campbell, T. F. (1998). Nonword Repetition and Child Language Impairment. Journal of Speech, Language, and Hearing Research, 41(5), 1136-1146. 
Duffy, J. R. (1995). Motor speech disorders: Substrates, differential diagnosis, and management. St. Louis, MO: Mosby.

Glenberg, A. M. (1977). Influences of retrieval processes on the spacing effect in free recall. Journal of Experimental Psychology: Learning, Memory, and Cognition, 3, 282-294.

Goode, S., \& Magill, R. A. (1986). The contextual interference effects in learning three badminton serves. Research Quarterly for Exercise and Sport, 57, 308-314.

Hall, K. G., Domingues, D. A., \& Cavazos, R. (1994). Contextual Interference Effects with Skilled Baseball Players 1, 2. Perceptual and Motor Skills, 78(3), 835-841.

Hebert, E. P., Landin, D., \& Solmon, M. A. (1996). Practice schedule effects on the performance and learning of low-and high-skilled students: An applied study. Research Quarterly for Exercise and Sport, 67(1), 52-58.

Horak, M. (1992). The Utility of Connectionism for Motor Learning: A Reinterpretation of Contextual Interference in Movement Schemas. Journal of Motor Behavior, 24(1), 58-66. https://doi.org/10.1080/00222895.1992.9941601

Jarus, T., Wughalter, E. H., \& Gianutsos, J. G. (1997). Effects of contextual interference and conditions of movement task on acquisition, retention, and transfer of motor skills by women. Perceptual and Motor Skills, 84(1), 179-193.

Kaipa, R. (2013). Evaluation of principles of motor learning in speech and non-speech-motor learning tasks. Retrieved from http://ir.canterbury.ac.nz/handle/10092/10349

Kantak, S. S., \& Winstein, C. J. (2012). Learning-performance distinction and memory processes for motor skills: A focused review and perspective. Behavioural Brain Research, 228(1), 219-231. 
Knock, T. L., Ballard, K. J., Robin, D. A., \& Schmidt, R. A. (2000). Influence of order of stimulus presentation on speech motor learning: A principled approach to treatment for apraxia of speech. Aphasiology, 14(5/6), 653-668.

Kruisselbrink, L. D., \& Van Gyn, G. H. (2011). Task characteristics and the contextual interference effect. Perceptual and Motor Skills, 113(1), 19-37.

Landin, D., Hebert, P., \& Menickelli, J. (2003). INTERFERENCE IS BEST FOR ADULT NOVICES? Journal of Hunzan Movement Studies, 44, 019-035.

Lee, T. D., \& Magill, R. A. (1985). Can forgetting facilitate skill acquisition? In R. B. Wilberg \& I. M. Franks (Eds.), Differing perspectives in motor learning, memory, and control (pp. 322). Amsterdam: North Holland.

Lee, T. D., \& Simons, D. A. (2004). Contextual interference. In Skill Acquisition in Sport: Research, Theory and Practice. Routledge.

Lee, T. D., Wishart, L. R., Cunningham, S., \& Carnahan, H. (1997). Modeled timing information during random practice eliminates the contextual interference effect. Research Quarterly for Exercise and Sport, 68(1), 100-105.

Lee, T. D., Wulf, G., \& Schmidt, R. A. (1992). Contextual interference in motor learning: Dissociated effects due to the nature of task variations. The Quarterly Journal of Experimental Psychology, 44(4), 627-644.

Lin, C. H., Fisher, B. E., Winstein, C. J., Wu, A. D., \& Gordon, J. (2008). Contextual interference effect: Elaborative processing or forgetting-reconstruction? A post hoc analysis of transcranial magnetic stimulation-induced effects on motor learning. Journal of Motor Behavior, 40(6), 578-586. 
Maas, E., Robin, D. A., Austermann-Hula, S. N., Wulf, G., Ballard, K. J., \& Schmidt, R. A. (2008). Principles of motor learning in treatment of motor speech disorders. American Journal of Speech-Language Pathology, 17, 277-298.

Magill, R. A., \& Hall, K. G. (1990). A review of the contextual interference effect in motor skill acquisition. Human Movement Science, 9(3-5), 241-289. https://doi.org/10.1016/01679457(90)90005-X

Meigh, K. M. (2014, September 10). Rule- versus instance-based learning in speech-like behavior: An evaluation of transfer and motor class effects [University of Pittsburgh ETD]. Retrieved April 2, 2015, from http://d-scholarship.pitt.edu/22244/

Meigh, K. M. (2017). A Novel Investigation of GMP Theory: Syllable Stress as a Motor Class Variable. Journal of Speech \& Hearing Research, 60(6S), 1685-1694.

Meigh, K. M., \& Shaiman, S. (2010). Evaluation of a comparable control parameter for speech and nonspeech: The effect of amount of practice on intraoral pressure accuracy. Poster presented at the Motor Speech Conference, Savannah, GA.

Russell, D. M., \& Newell, K. M. (2007). How persistent and general is the contextual interference effect? Research Quarterly for Exercise and Sport, 78(4), 318-327.

Schmidt, R. A. (1975). A schema theory of discrete motor skill learning. Psychological Review, 82(4), 225.

Schmidt, R. A., \& Lee, T. D. (2005). Motor Control and Learning: A Behavioral Emphasis (4th ed.). Champagne, IL: Human Kinematics.

Schneider, W., Eschman, A., \& Zuccolotto, A. (2002). Eprime User's Guide (Version 2.0). Pittsburgh: Psychology Software Tools, Inc. 
Secord, W. (1981). Test of minimal articulation competence. San Antonio, TX: Psychological Corporation.

Shea, C. H., Kohl, R., \& Indermill, C. (1990). Contextual interference: Contributions of practice. Acta Psychologica, 73(2), 145-157. https://doi.org/10.1016/0001-6918(90)90076-R

Shea, J. B., \& Morgan, R. L. (1979). Contextual interference effects on the acquisition, retention, and transfer of a motor skill. Journal of Experimental Psychology: Human Learning and Memory, 5, 179-187.

Shewokis, P. A., Del Rey, P., \& Simpson, K. J. (1998). A test of retroactive inhibition as an explanation of contextual interference. Research Quarterly for Exercise and Sport, 69(1), $70-74$.

Simon, D. A., \& Bjork, R. A. (2002). Models of performance in learning multisegment movement tasks: consequences for acquisition, retention, and judgments of learning. Journal of Experimental Psychology: Applied, 8(4), 222.

SPSS. (2012). IBM SPSS Statistics for Windows. Armonk, NY: IBM Corp.

Tillman, T. W., \& Carhart, R. (1966). An expanded test for speech discrimination utilizing CNC monosyllabic words: Northwestern University Auditory Test No. 6. DTIC Document. $\begin{array}{ll}\text { Retrieved } & \text { from }\end{array}$ http://oai.dtic.mil/oai/oai?verb=getRecord\&metadataPrefix=html\&identifier=AD063963 8

Travlos, A. K. (2010). Specificity and variability of practice, and contextual interference in acquisition and transfer of an underhand volleyball serve. Perceptual and Motor Skills, 110(1), 298-312. 
Tremblay, S., Houle, G., \& Ostry, D. J. (2008). Specificity of speech motor learning. The Journal of Neuroscience: The Official Journal of the Society for Neuroscience, 28(10), 2426-2434. https://doi.org/10.1523/JNEUROSCI.4196-07.2008

Wagner, R. K., Torgesen, J. K., Rashotte, C. A., \& Pearson, N. A. (2013). CTOPP-2: Comprehensive Test of Phonological Processing. Austin, TX: Pro-Ed.

Wifall, T., McMurray, B., \& Hazeltine, E. (2014). Perceptual similarity affects the learning curve (but not necessarily learning). Journal of Experimental Psychology. General, 143(1), 312331. https://doi.org/10.1037/a0030865

Wood, C. A., \& Ging, C. A. (1991). The Role of Interference and Task Similarity on the Acquisition, Retention, and Transfer of Simple Motor Skills. Research Quarterly for Exercise and Sport, 62(1), 18-26. https://doi.org/10.1080/02701367.1991.10607514

Wright, D. L., Li, Y., \& Whitacre, C. (1992). The contribution of elaborative processing to the contextual interference effect. Research Quarterly for Exercise and Sport, 63(1), 30-37.

Young, D. E., Cohen, M. J., \& Husak, W. S. (1993). Contextual interference and motor skill acquisition: On the processes that influence retention. Human Movement Science, 12(5), $577-600$. 


\section{APPENDIX A: PRE-SCREENING LANGUAGE QUESTIONNAIRE \\ When you were learning to speak as a child, did you learn any language other than English?}

YES: a.) Did you speak more than a few phrases at home?

YES: Not eligible for the study

NO: Still Eligible, continue with question b.)

b.) Did you understand more than a few phrases at home?

YES: Not eligible for the study

NO: Eligible for the study

NO: Did anyone in your family, like your parents or grandparents, speak a language other than English?

YES: a.) Did you ever speak more than a few phrases to them in that language?

YES: Not eligible for the study

NO: Still Eligible, continue with question b.)

b.) Did you understand more than a few phrases when they were speaking that language?

YES: Not eligible for the study

NO: Eligible for the study

NO: Eligible for the study

Have you taken more than $\mathbf{2}$ semesters of a foreign language?

YES: Likely not eligible for the study, contact Dr. Meigh

NO: Eligible for the study 
APPENDIX B: STIMULI

TRAINING STIMULI

TABLE 3: TRAINING SIMILAR STIMULI

\begin{tabular}{|c|c|c|}
\hline Meigh (2017) Stimuli & Syllable Stress & Similar Training Stimuli \\
\hline Training Set & 2 & /tenærok/ \\
\hline Training Set & 1 & /kæ0otæs/ \\
\hline Training Set & 1 & /sæa $\theta$ odæk/ \\
\hline Training Set & 1 & /zotenav/ \\
\hline Training Set & 2 & /za」’dzəz/ \\
\hline Transfer Set 1 & 1 & /næterok/ \\
\hline Transfer Set 1 & 2 & /சokætæs/ \\
\hline Transfer Set 1 & 2 & /өosædæk/ \\
\hline Transfer Set 1 & 2 & /tezonav/ \\
\hline Transfer Set 1 & 1 & /£ozadzəz/ \\
\hline
\end{tabular}

TABLE 4: TRAINING DISSIMILAR STIMULI

\begin{tabular}{|c|c|c|}
\hline Meigh (2017) Stimuli & Syllable Stress & Dissimilar Training Stimuli \\
\hline Transfer Set 2 & 1 & /ఏ2dzəzod/ \\
\hline Transfer Set 2 & 1 & 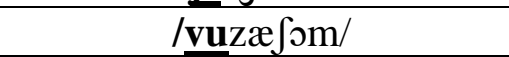 \\
\hline Transfer Set 2 & 1 & /fozæ $\int \mathrm{d} d /$ \\
\hline Transfer Set 2 & 1 & /kozæ $\int \mathrm{om} /$ \\
\hline Transfer Set 2 & 2 & /rasæ$\theta$ on/ \\
\hline Transfer Set 3 & 2 & /gibıðıb/ \\
\hline Transfer Set 3 & 2 & /zibutfed/ \\
\hline Transfer Set 3 & 1 & /t的ðuguz/ \\
\hline Transfer Set 3 & 1 & /zogijub/ \\
\hline Transfer Set 3 & 2 & /gugiðutfl \\
\hline
\end{tabular}


TRANSFER STIMULI

TABLE 5: SIMILAR TRANSFER STIMULI

\begin{tabular}{|c|c|c|}
\hline Meigh (2017) Stimuli & Syllable Stress & $\begin{array}{c}\text { Similar Transfer } \\
\text { Stimuli } \\
\end{array}$ \\
\hline Training Set & 2 & 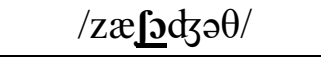 \\
\hline Training Set & 2 & /djəżzzæk/ \\
\hline Training Set & 2 & /zæn’dzə $\theta$ / \\
\hline Training Set & 2 & /dzıñzæk/ \\
\hline Training Set & 1 & 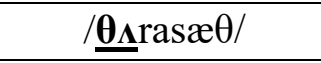 \\
\hline Transfer Set 1 & 1 & 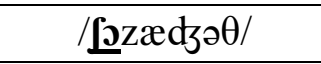 \\
\hline Transfer Set 1 & 1 & /żodzəzæk/ \\
\hline Transfer Set 1 & 1 & 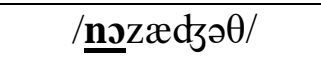 \\
\hline Transfer Set 1 & 1 & 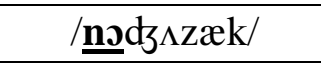 \\
\hline Transfer Set 1 & 2 & $/ \mathrm{ra \theta} \underline{\boldsymbol{\theta}} \mathrm{s} æ \theta /$ \\
\hline
\end{tabular}

\section{TABLE 6: DISSIMILAR TRANSFER STIMULI}

\begin{tabular}{|c|c|c|}
\hline Meigh (2017) Stimuli & Syllable Stress & Dissimilar Transfer Stimuli \\
\hline Transfer Set 2 & 1 & /næOodæp/ \\
\hline Transfer Set 2 & 1 & /d्dodzozod/ \\
\hline Transfer Set 2 & 2 & /sıvenæ $\theta /$ \\
\hline Transfer Set 2 & 2 & /nasæaof/ \\
\hline Transfer Set 2 & 2 & /vi@ə̈dæk/ \\
\hline Transfer Set 3 & 1 & /bıðetfug/ \\
\hline Transfer Set 3 & 1 & /gigひðib/ \\
\hline Transfer Set 3 & 1 & /t的jiwız/ \\
\hline Transfer Set 3 & 2 & /botfitfez/ \\
\hline Transfer Set 3 & 2 & /tfơtfubiz/ \\
\hline
\end{tabular}

